\title{
Comment on "Thinner temporal peripapillary retinal nerve fibre layer in Stargardt disease detected by optical coherence tomography"
}

\author{
Pradeep Kumar Panigrahi ${ }^{1}$
}

Received: 16 June 2021 / Revised: 16 June 2021 / Accepted: 22 June 2021 / Published online: 5 July 2021

(c) The Author(s), under exclusive licence to Springer-Verlag GmbH Germany, part of Springer Nature 2021

\section{Dear Editor,}

With great interest, I went through the article titled "Thinner temporal peripapillary retinal nerve fibre layer in Stargardt disease detected by optical coherence tomography" by Reich $\mathrm{M}$ et al. [1]. I would like to congratulate the authors on their excellent work. The authors have reported thinner peripapillary retinal nerve fibre layer thickness in the sector of axons projecting to the degenerated macular area. I have a few comments. In the methodology, authors have described the study design to be cross-sectional, monocentric, observational, case-control study. Case-control studies are designed to determine if an exposure is associated with disease or condition of interest (outcome) [2]. In this type of study, cases (patients with outcome) and controls (patients who are free of the outcome) are identified first. Following this, information is collected retrospectively to know which subject in which group had the exposure. Finally, the frequency of exposure in both groups is compared. Case-control studies are quick, easy and inexpensive to perform. They are particularly appropriate for investigating outbreaks and studying rare diseases and outbreaks. The strength of association between exposure and outcome is expressed in terms of odds ratio. Case-control studies do not provide much information about the incidence or prevalence of disease.

In the present study, a cross-section of patients with Stargardt's disease was designated to be cases and normative data from the machine was the control group. All measurements of ocular parameters were done at a single point of time with no longitudinal follow-up. This study did not go back retrospectively and study any exposure which is done classically in case-control studies. Just having a control group does not mean that the study is a case-control study. The present study is a cross-sectional, single centre (monocentric), observational study. It is not a case-control study at all. There are reports that systemic intake of drugs like isotretinoin and vigabatrin can be associated with peripapillary retinal nerve fibre layer thinning [3, 4]. A statement could have been added that patients taking such drugs were excluded from the study.

\section{Declarations}

Competing interests The authors declare no competing interests.

\section{References}

1. Reich M, Lübke J, Joachimsen L et al (2021) Thinner temporal peripapillary retinal nerve fibre layer in Stargardt disease detected by optical coherence tomography. Graefes Arch Clin Exp Ophthalmol 259:1521-1528. https://doi.org/10.1007/s00417-020-04992-2

2. Lewallen S, Courtright P (1998) Epidemiology in practice: casecontrol studies. Community Eye Health 11(28):57-58

3. Yılmaz U, Küçük E, Koç Ç et al (2017) Investigation of the effects of systemic isotretinoin treatment on retinal nerve fiber layer and macula. J Dermatolog Treat 28:314-317. https://doi.org/10.1080/ 09546634.2016.1254146

4. Peng Y, Zhao Y, Hu W et al (2017) Reduction of retinal nerve fiber layer thickness in vigabatrin-exposed patients: a meta-analysis. Clin Neurol Neurosurg 157:70-75. https://doi.org/10.1016/j. clineuro.2017.04.004

Publisher's note Springer Nature remains neutral with regard to jurisdictional claims in published maps and institutional affiliations.

Pradeep Kumar Panigrahi

doc.pkp25@gmail.com

1 Department of Ophthalmology, Institute of Medical Sciences

\& SUM Hospital, Sikshya O Anusandhan (Deemed To Be)

University, 8-Kalinga Nagar, Bhubaneswar 751003, India 